\title{
Families’ and Victims' Characteristics Influencing Child Sexual Abuse
}

\author{
Mona Hassan ${ }^{1 *}$, Cheryl Killion ${ }^{2}$, Linda Lewin ${ }^{3}$, Vicken Totten ${ }^{4}$ and Gary Faye ${ }^{2}$ \\ ${ }^{1}$ College of Nursing, Texas Woman's University, Houston, Texas, USA \\ ${ }^{2}$ Francis Bolton School of Nursing, Case Western Reserve University, Ohio, USA \\ ${ }^{3}$ College of Nursing, Wayne State University, Detroit, Michigan, USA \\ ${ }^{4}$ Kaweah Delta Health Care District, Visalia, California, USA
}

\begin{abstract}
The purpose: Child sexual abuse is considered an important national public health problem that must be addressed with a sense of urgency. This paper was to provide a comprehensive information on the child and family characteristics which may influence the vulnerability of child sexual abuse
\end{abstract}

Recent findings: Underreporting of child sexual abuse may be due to family's and children's and their families' characteristics. These include their demographics and personal characteristics.

Summary: The important role of healthcare providers as well as parents to be aware of children's and families' characteristics which may influence child sexual abuse. It is discussed along with implications for praxis.

Keywords: Characteristics; Child disclosure; Psychological trauma; Sexual abuse

\section{Introduction}

Child sexual abuse is considered an important national public health problem that must be addressed with a sense of urgency [1]. Unfortunately, many incidents of child sexual abuse go unreported [2]. Therefore, US Department of Health and Human Services (USDHHS) reported that actual rates of sexual abuse are thought to be much higher than those recorded in official records [3]. The most informative official sources of data are those that provide the number of reported or substantiated cases of child sexual abuse in the US and all over the world. Significantly, though, these data have been severely criticized as underreporting the incidence of child sexual abuse. There is a large discrepancy between official data and prevalence estimates based on retrospective studies, which always report higher rates. The World Health Organization (WHO) estimates one in five women and one in thirteen men report having been sexually abused as a child every year in the world community [4]. These astounding numbers suggest that sexual abuse is an unfortunate part of the lives of many children in communities all over the world. The United States Department of Health and Human Services (USDHHS) reported that in 2010 alone, 63,527 American children were reported having been sexually abused [5]. Oftentimes, unreported cases of sexual abuse can be identified by researching familial characteristics and reported health histories, and through assessing and treating individuals who manifest psychological despair and/or abuse of alcohol and drugs [6]. Families' and children's characteristics play important roles in disclosing and treating sexually abused cases [7].

This trend is believed to have been in existence for decades [8,9]. Some children may lack adequate supervision and parental support. Nevertheless, any person who experienced sexual abuse in childhood, regardless of his/her demographic profile, tends to manifest insecure family relationships, fears, and unresolved traumas. This mix of emotions and thoughts may negatively impact the victim's life and his/her potential for positive personal growth and development because the family-related traumas extend into adulthood and are often transmitted from one generation to the next $[1,10,11]$. In order to detect and treat the abused children, it is important for the health care providers to have a holistic view of the problem, including being sensitive to the child-victims' and their families' characteristics which may influence on the reporting on child sexual abuse [12,13].

This article will survey the existing scholarship literature review of child-victims' and their family's characteristics. Research is needed that include demographics and characteristics of both child- victims and their families. It may be possible to provide a clearer picture of child sexual abuse. This could help to detect vulnerable children who are at risk for this horrific experience. As a result, this article may help in early detection and prompt intervention for the sexually abused children and families.

\section{Demographic Characteristics Family socio-demographics}

Priebe and Svedin found that sexually abused children were less likely to live with both parents and more likely to live in families of low socioeconomic status [14]. In a similar study, Bernard-Bonnin, Hébert, Daignault, and Allard-Dansereau compared 67 girls with a history of child sexual abuse to 67 girls without a history of child sexual abuse [15]. They found that girls who had experienced child sexual abuse were less likely to have parents with higher education and socioeconomic levels than the control group. Ramírez, Pinzón-Rondón, and Botero interviewed 1,089 mothers in order to identify maternal risk factors for child sexual abuse. Low income and education were risk factors; and older and non-employed mothers were less willing to report child sexual abuse [16]. Poor communication between parent and child increased the chances late disclosure on sexual abuse incidents. Laaksonen et al. suggested that family problems such as biological parents'

*Corresponding author: Mona Hassan, Collage of Nursing, Texas Woman's University, 6700 Fannin, Houston, TX 77030, USA, Tel: 1 216-269-4343; E-mail: mah106@case.edu

Received July 07, 2015; Accepted September 18, 2015; Published September 26, 2015

Citation: Hassan M, Killion C, Lewin L, Totten V, Faye G (2015) Families' and Victims' Characteristics Influencing Child Sexual Abuse. J Trauma Treat S4: 023. doi:10.4172/2167-1222.S4-023

Copyright: ( 2015 Hassan M, et al. This is an open-access article distributed under the terms of the Creative Commons Attribution License, which permits unrestricted use, distribution, and reproduction in any medium, provided the original author and source are credited. 
alcohol abuse, substance abuse, and lack of supervision increased the risk of child sexual abuse [17]. Finkelhor, Turner, Ormrod, and Hamby added that low socioeconomic status, low educational attainment, and unemployment negatively influence parents' ability to protect and care for their children, which, in turn, negatively influences child rearing and increases psychological damage from child sexual abuse [18].

\section{Victim's gender differences}

The relationship between gender and outcome may depend on characteristics of the children and the consequences being measured. However, findings concerning the relationships between gender of the victim and frequency of child sexual abuse have been mixed [19]. Kinner argues that, because boys are physically stronger and tend to protect themselves more than girls, young female victims are more likely to be forced than are male victims [20,21]. Male perpetrators are more able to use their physical strength to control and limit the child-victims' resistance, in order to satisfy their attachment needs and intimacy desires, which fail to be satisfied through normal relationships [22]. Ranney et al. hypothesized that boys might be more reluctant to report the sexual abuse. Boys may have fears related to their identities as males or the possibilities of being labeled as homosexual or other types of sexual deviants [23]. Therefore, sexually abused male child-victims are perhaps under-reported. For female child-victim, Gibson and Leitenberg conducted a survey of 106 women with a history of child sexual abuse [24]. They reported high prevalence of unwanted sexual activities: $45 \%$ experienced force, $7 \%$ experienced threats of physical force, and $48 \%$ were given drugs or alcohol before sexual intercourse. All of the female victims in the study reported powerlessness as the main psychological problem that they experienced.

\section{Victims' age differences}

The histories of children younger than 15 years were different from those of adolescents 15 to 17 years old. For example, women who experienced child sexual abuse as younger victims reported genital touching, attempted penile-vaginal intercourse, and completed penilevaginal intercourse by the perpetrator. However, the adolescent victims experienced a greater range of activities: genital touching, oral sex, vaginal penetration with an object or finger, vaginal intercourse, anal penetration with a finger, and anal intercourse [24]. Furthermore, Modelli, Galvão, and Pratesi reported that boys are at higher risk for sexual abuse when they are below the age of 6.5 years [25].

\section{Victim's Ethnic Differences}

Victims' ethnicity and culture may influence the childhood experience of sexual abuse [26]. In a study of 142 college students, Lauterbach, Somer, Dell, and Vondeylen found that $30.9 \%$ of American students had a history of child sexual abuse; however, only $4.1 \%$ of Israeli students reported child sexual abuse [27]. In another study of 94 African American and Latino adults, Sciolla et al. asked child-victims of sexual abuse to reflect on their experiences in later life [28]. They found that African Americans described more externalizing behaviors such as anger and physical aggression; however, Latino respondents reported more internalizing behaviors such as depression and isolation. In contrast, in a survey of 1,698 young adults (ages 19-20), Trent, Clum, and Roche found no behavioral differences based on ethnicity when describing their findings about victims of child sexual abuse [29].

\section{Personal Characteristics}

\section{Family protection}

Parental perceptions of sexual abuse may differ depending on their own characteristics as well as those of their children. Pullins and Jones found that parents paid more attention to behavioral and physical symptoms in preadolescent children than in adolescents; physical and sexual symptoms in adolescents may have been disregarded because parent thought their children may be sexually active $[1,30]$. Family members/ caregivers play an important role in supporting and protecting their children. Afifi and Macmillan studied family environment and child abuse [31]. They concluded that families with sexual abuse histories were considered less cohesive and had fewer or no household rules, and there was a general lack of mutual responsibility among household members regarding the protection of their children. Families in which child abuse occurs are also more likely to have ill-defined boundaries and a lack of limit-setting [1]. In addition, family members with sexual abuse histories were less likely to encourage personal and independent growth and development. For instance, Möhler et al. reported that mothers with a history of child physical or sexual abuse themselves were more likely to abuse their children [32]. These mothers may also react negatively to their children's disclosure of sexual abuse and not support them [33].

\section{Response to the child-victim disclosure}

Sometimes inappropriate familial responses to child sexual abuse can delay a victim's disclosure. For females, the perpetrator is often a friend of the family or the mother's sexual partner [6], and in this case, the child risks losing support from the mother by disclosing. The family's response to the child's sexual abuse may be influenced by the family's perceptions of their children's credibility or by the family's emotional connection to the perpetrator. That is to say, if the family does not perceive this act as being a realistic possibility, they may interpret the report as an indicator of the child's disrespect for elders or as an attempt to disrupt the family by untruthfully reporting sexual abuse. In these instances, the child will probably not receive support from the adults in the family and his/her sense of trust will deteriorate even further [34].

Victims of child sexual abuse tend to have fewer problems if their parents believe their disclosure and support them in the long process that is required to overcome the resulting psychological and emotional trauma [33]. For instance, family reaction to the victim of child sexual abuse determines his/her experience of externalizing and internalizing behavioral problems. It is generally recognized that adults with a history of child sexual abuse manifest behaviors that are consistent with clinical descriptions of early abuse experiences [35]. For instance, in their sample of 122 women with a history of child sexual abuse, Jonzon and Lindblad found that the majority of victims had had a close relationship with the perpetrator, were abused before the age of 6 , and had sexual contact with penetration [36]. In addition, these victims were sexually abused a few times a month. The previous study explains how the relationship of the family and the child to the perpetrator can heavily influence the disclosure of sexual abuse of young children [37]. For instance, the child-victim's fear, guilt, and shame may prevent him/her from reporting the sexual assault [38]. Furthermore, in cases of intrafamilial sexual abuse, the child experiences negative caregiver reactions such as being deprived of physical and emotional care that he/she has become accustomed to receiving when he/she discloses the sexual abuse activities of a family member. In addition, many times the family member may reprimand the abused child, protect the perpetrator, and place the abused child in a position of family scapegoat by other members. These responses often hinder the children from reporting the abuse [39] and the child experience sexual abuse for a longer duration and suffers more severe physical and mental damage [40]. 


\section{Conclusion}

In sum, a theoretical review on child sexual abuse provides guidelines for health care providers who are challenged to be more sensitive to the child-victims' such as gender, age, and ethnicity as well as their families' characteristics such as socio-demographics, protection and response to their sexually abused children. Underreported cases are in a bad need for early detection and treatment. This theoretical information presents a continuous dialogue about children who experienced sexual abuse and identify the social environment which may influence the occurrence of child sexual abuse. This theoretical overview also provides preliminary information about the important role of parents/families to protect their children.

\section{Recommendations}

Given the literature review on the child-victim' and family' characteristics influencing child sexual abuse, including demographic and personal features, the findings from this study indicate the need for the intensification of efforts that address the prevention, early detection, and prompt intervention for these children. Parents and caregivers should be sensitive to their young children's vulnerability. Children will require that family, friends, and health care providers be more diligent about keeping these young children and youth safe and out of harm's way. In addition, involving the general public though increasing their awareness about child sexual abuse could help to decrease the incidence of this devastating experience. Policymakers and practitioners to redouble their efforts to protect child victims. Child protective services should ensure the child-victim's safety in order to prevent revictimization [41].

Finally, the researchers recommend the further studies be done to determine the emotional, psychological, and physical impact that child sexual abuse, and the specific therapeutic approaches that provide the best treatment outcomes [42,43].

\section{References}

1. Miller-Perrin CL, Perrin RD (2007) Child maltreatment: An introduction. Sage Publications, London, UK.

2. Lippert T, Cross T, Jones L, Walsh W (2009) Telling interviewers about sexual abuse: Predictors of child disclosure at forensic interviews. Child Maltreat 14: 100-113.

3. US Department of Health and Human Services (USDHHS) (2010) child maltreatment.

4. World Health Organization (WHO) (2014) Child Maltreatment.

5. US Department of Health and Human Services (USDHHS) (2012) Testimony.

6. Pipe M, Lamb M, Orbach Y, Cederborg A (2007) Child sexual abuse: Disclosure, delay, and denial. Lawrence Erlbaum Associates, Mahwah, NJ, USA.

7. Dorahy MJ, Clearwater K (2012) Shame and guilt in men exposed to childhood sexual abuse: a qualitative investigation. J Child Sex Abus 21: 155-175.

8. Goodyear-Brown P (2012) Handbook of child sexual abuse: Identification, assessment, and treatment. John Wiley \& Sons, Hoboken, NJ, USA.

9. Gordon H, Connolly D (2009) Failing to report details of an event: A review of the directed forgetting procedure and applications to reports of childhood sexual abuse. Memory 13: 1-14.

10. Jonsson PV (2009) Complex trauma, impact on development and possible solutions on an adolescent intensive care unit. Clin Child Psychol Psychiatry 14: $437-454$

11. Troiano M (2011) Child abuse. Nurs Clin North Am 46: 413-422.

12. McGregor K, Glover M, Gautam J, Jülich S (2010) Working sensitively with child sexual abuse survivors: what female child sexual abuse survivors want from health professionals. Women Health 50: 737-755.
13. Finkel MA (2012) Children's disclosures of child sexual abuse. Pediatr Ann 41 e1-6.

14. Priebe G, Svedin CG (2009) Prevalence, characteristics, and associations of sexual abuse with sociodemographics and consensual sex in a populationbased sample of Swedish adolescents. J Child Sex Abus 18: 19-39.

15. Bernard-Bonnin A, Hébert M, Daignault I, Allard-Dansereau C (2008) Disclosure of sexual abuse, and personal and familial factors as predictors of post-traumatic stress disorder symptoms in school-aged girls. Pediatrics and Child Health 13: 479-486.

16. Ramírez C, Pinzón-Rondón AM, Botero JC (2011) Contextual predictive factors of child sexual abuse: the role of parent-child interaction. Child Abuse Negl 35 1022-1031.

17. Laaksonen $T$, Sariola $H$, Johansson $A$, Jern $P$, Varjonen $M$, et al. (2011) Changes in the prevalence of child sexual abuse, its risk factors, and their associations as a function of age cohort in a Finnish population sample. Child Abuse Negl 35: 480-490.

18. Finkelhor D, Turner H, Ormrod R, Hamby SL (2010) Trends in childhood violence and abuse exposure: evidence from 2 national surveys. Arch Pediatr Adolesc Med 164: 238-242.

19. Kouyoumdjian H, Perry A, Hansen D (2009) Non-offending parent expectations of sexually abused children: Predictive factors and influence on children's recovery. Journal of Child Sexual Abuse 18: 40-60.

20. Kinner K (2007) Childhood sexual abuse: a reference handbook (2ndedn) Santa Barbara, CA: ABC-Clio, LLC Kisanga F, Nystrom L, Hogan N, Emmelin $M$ (2011) Child sexual abuse: Community concerns in urban Tanzania. Journal of Child Sexual Abuse 20: 196-217.

21. Deering R, Mellor D (2011) An exploratory qualitative study of the self-reported impact of female-perpetrated childhood sexual abuse. J Child Sex Abus 20 58-76

22. Miner M, Robinson B, Knight R, Berg D, Romine R, et al. (2010) Understanding sexual perpetration against children: Effects of attachment style, interpersonal involvement, and hypersexuality. Sex Abuse 22: 58-77

23. Ranney M, Whiteside L, Walton M, Chermack S, Zimmerman M, et al. (2011) Sex differences in characteristics of adolescents presenting to the emergency department with acute assault-related injury. Acad Emerg Med 18: 1027-1035.

24. Gibson LE, Leitenberg $H$ (2001) The impact of child sexual abuse and stigma on methods of coping with sexual assault among undergraduate women. Child Abuse Negl 25: 1343-1361.

25. Modelli ME, Galvão MF, Pratesi R (2012) Child sexual abuse. Forensic Sci Int 217: 1-4.

26. Hershkowitz I, Lanes O, Lamb ME (2007) Exploring the disclosure of child sexual abuse with alleged victims and their parents. Child Abuse Negl 31: 111-123.

27. Lauterbach D, Somer E, Dell P, Vondeylen H (2008) Abuse history and pathological dissociation among Israeli and American college students: a comparative study. J Trauma Dissociation 9: 51-62.

28. Sciolla A, Glover DA, Loeb TB, Zhang M, Myers HF, et al. (2011) Childhood sexual abuse severity and disclosure as predictors of depression among adult African-American and Latina women. J Nerv Ment Dis 199: 471-477.

29. Trent M, Clum GB, Roche K (2007) Sexual victimization and reproductive health outcomes in urban youth. Ambul Pediatr 7: 313-316.

30. Pullins LG, Jones JD (2006) Parental knowledge of child sexual abuse symptoms. J Child Sex Abus 15: 1-18.

31. Afifi TO, Macmillan HL (2011) Resilience following child maltreatment: a review of protective factors. Can J Psychiatry 56: 266-272.

32. Möhler E, Matheis V, Poustka L, Marysko M, Finke P, et al. (2009) Mothers with a history of abuse tend to show more impulsiveness. Child Abuse Negl 33: 123-126.

33. Colton M, Roberts S, Vanstone M (2010) Sexual abuse by men who work with children. J Child Sex Abus 19: 345-364.

34. OgÅ,odek E, Araszkiewicz A (2011) [The Jung model of active style of schema] Pol Merkur Lekarski 31: 378-380.

35. Asgeirsdottir BB, Sigfusdottir ID, Gudjonsson GH, Sigurdsson JF (2011) Associations between sexual abuse and family conflict/violence, self-injurious 
Citation: Hassan M, Killion C, Lewin L, Totten V, Faye G (2015) Families' and Victims' Characteristics Influencing Child Sexual Abuse. J Trauma Treat S4: 023. doi:10.4172/2167-1222.S4-023

Page 4 of 4

behavior, and substance use: the mediating role of depressed mood and anger. Child Abuse Negl 35: 210-219.

36. Jonzon E, Lindblad F (2004) Disclosure, reactions, and social support: findings from a sample of adult victims of child sexual abuse. Child Maltreat 9: 190-200.

37. London K, Bruck M, Wright D, Ceci S (2008) Review of the contemporary literature on how children report sexual abuse to others: Findings, methodological issues, and implications for forensic interviewers. Memory 16: $29-47$

38. McNally RJ (2007) Betrayal trauma theory: a critical appraisal. Memory 15 : 280-294.

39. Sinanan AN (2011) The impact of child, family, and child protective services factors on reports of child sexual abuse recurrence. J Child Sex Abus 20: 657-676.

40. Gilbert R, Widom CS, Browne K, Fergusson D, Webb E, et al. (2009) Burden and consequences of child maltreatment in high-income countries. Lancet 373 $68-81$

41. Fortin K, Jenny C (2012) Sexual abuse. Pediatr Rev 33: 19-32.

42. Hart S, Glaser D (2011) Psychological maltreatment: Maltreatment of the mind: A catalyst for advancing child protection toward proactive primary prevention and promotion of personal well-being. Child Abuse Negl 35: 758-766.

43. Hart S, Lee $Y$, Wernham M (2011) A new age for child protection-General comment 13: Why it is important, how it was constructed, and what it intends? Child Abuse Negl 35: 970-978.
This article was originally published in a special issue, Post Traumatic Stress Disorders handled by Editor(s). Dr. Allison N. Sinanan, Stockton University, NJ, USA 